\title{
Diversity Leadership: Influence of Ethnicity, Gender, and Minority Status
}

\author{
Jean Lau Chin \\ Adelphi University, New York, USA \\ Email: chin@adelphi.edu \\ Received January $7^{\text {th }}, 2013$; revised February $8^{\text {th }}, 2013$; accepted February $16^{\text {th }}, 2013$
}

\begin{abstract}
Leadership research is often silent about how race and ethnicity influence the exercise of leadership and does not include the experiences of racial/ethnic minority leaders. Leaders from five racial/ethnic groups within the US were surveyed on their endorsement of leadership dimensions as defined by the GLOBE studies and the influence of their race, ethnicity and gender on the exercise of leadership in this exploratory study. While all leaders endorsed common leadership dimensions, cultural variation emerged on a factor consistent with a humane orientation and collaborative leadership style. Leaders of color and women leaders strongly embraced their ethnic and gender identities compared with White male leaders. These social identities together with lived experiences associated with minority status were perceived as influencing their exercise of leadership, presenting both challenges and strengths. Differences in the leadership profile of this diverse leadership sample with the Anglo group in the GLOBE studies suggest the importance of examining diversity in leadership. Conceptualizations of leadership need to be inclusive of the social identities and lived experiences that leaders and followers both bring to the contexts of leadership.
\end{abstract}

Keywords: Diversity Leadership; Social Identities and Leadership; Minority Status and Leadership

\section{Introduction}

As societies and organizations become increasingly diverse in the US and globally, it becomes important to understand how the social identities of our leaders (i.e., race, ethnicity, gender, and minority status) interact to influence the exercise of leadership. Social identities generally influence our behaviors in social and interpersonal domains and are likely to influence leader identity and behaviors. Yet, current leadership theories are biased in reflecting the structures and cultures of North American organizations run by White, Anglo, heterosexual men (Den Hartog \& Dickson, 2004). As more women and racial/ethnic minorities join the ranks of leadership, leadership studies need to be more heterogeneous in studying variations across race, ethnicity, gender or other dimensions of diversity to understand the complexities of behaviors associated with effective leadership (Chin \& Sanchez-Hucles, 2007).

Variations in sociocultural contexts and the lived experiences of both leaders and their members may well influence the nature of the leader-member exchange. Lived experiences associated with acculturation, discrimination, racism, and biculturalism may well shape the values leaders bring and the goals they pursue. Among them, cultural affiliation groups often result in designation of dominant-minority status across different social identities. This raises issues of power and privilege, has posed access barriers and contributed to inter-group miscommunication among leaders with diverse social identities. Fassinger, Shullman, \& Stevenson (2010) frame the importance of affirming identity as an important leadership strategy among LGBT leaders given their historic marginalization because of sexual orientation. Eagly \& Carli's (2007) extensive work on women and leadership suggest that gender does influence the exercise of leadership. The perceived incongruity between female gen- der roles and leadership roles has led to less favorable and prejudicial appraisals of women leaders compared to men (Eagly \& Karau, 2002). Women leaders also perceive a need to adapt their behavioral style so men do not feel intimidated (Ragins, Townsend, \& Mattis, 1998) and experience a narrower range of acceptable behavior compared to male leaders (Eagly, Makhijani, \& Konsky, 1992). Intersectionality of gender and ethnicity has also been demonstrated to create dynamics that impact leadership such as constraining stereotypes, social role expectations, power and status differentials associated with these social identities. Pittinsky (2010) highlights how dominant-subordinate group relationships shape the intergroup exchange between leaders and members.

Most leadership studies, if inclusive of diverse leaders, treat them as special cases rather than as a potential source for theorizing from an important social context given the pervasiveness and impact of race in social experience (Ospina \& Foldy, 2009). In a review of studies drawn from educational leadership on the effects of race and ethnicity on leadership, they conclude that most studies viewed race as a constraint that must be managed (e.g., bias against and perceived marginality of leaders). A second set of studies viewed race as a personal resource in which leaders turn negative experiences (e.g., oppression) into constructive change in the exercise of leadership (e.g., drawing on their identity, trying to be more prototypic, or using code switching techniques). These studies treat race/ethnicity not only as an individual characteristic, but also as a social or political issue with personal and collective meaning. A third set of studies view how collective dimensions of social identity can also become a personal resource for many racial/ethnic leaders which includes grappling with power dynamics and the complexities of sociocultural contexts of which they are a part 
(Ospina \& Foldy, 2009). However, Eagly \& Chin (2010) suggest that current social and ecological contexts define gender and ethnic roles and behaviors in ways that may constrain and bias perceptions of leadership effecttiveness among women and diverse leaders of color. These studies suggest a view of leadership as a shared process embedded in social systems and organizational cultures (Yukl, 1989; Hackman \& Wageman, 2007) and the importance of social identities and lived experiences associated with variables of race, ethnicity, gender, and minority status in our conceptualizations of leadership. Despite these dimensions of diversity, women and racial/ethnic minority groups in the US share a common experience of minority status in the US in the ranks of leadership.

Cross-cultural studies of leadership have not addressed these variables of diversity or minority status since they have gene rally been limited to leaders operating under traditional Western cultural norms interacting with a non-Western workforce within multinational corporations (Kao, Sinha, \& Wilpert, 1999); in this sense, they have focused on dominant, Western, male leaders who need to alter their Western leadership styles to be effective with non-Western workforces.

Cultural variation in leadership is shown in a comprehensive series of cross-cultural studies known as the GLOBE studies (House, Hanges, Javidan, Dorfman, \& Gupta, 2004), which examine the leadership styles and national cultures of 62 countries via a survey of 17,000 middle managers from 951 organizations in the food processing, finance, and telecommunications industries. The GLOBE studies identified nine "universal" cultural orientation value dimensions (COV) that were empirically validated (see Table 1). The COV dimensions were then linked to six culturally endorsed leadership dimensions (CLT) associated with outstanding leadership (see Table 2).

The GLOBE studies draw on Implicit Leadership theory which posits that implicit beliefs and assumptions distinguish effective leaders from ineffective leaders (Lord \& Maher, 1991). Beliefs about leadership are viewed as related to cultural values and beliefs, and the cultural background or social context of the perceiver (Hofstede, 2001; Triandis, 1995). Cultural orientation values shared by members of a culture will result in variations in defining leadership prototypes (Gertsner \& Day, 1994). Leadership profiles for 10 regional clusters or societies identified by the GLOBE CLT dimensions and COV dimensions were shown to vary across cultures including a GLOBE Anglo profile and US profile presumably reflecting prototypic leader dimensions that are perceived to contribute to or impede outstanding leadership within Anglo cultures.

However, the GLOBE studies did not study subgroup profiles within countries. In fact, the methodology minimized diversity and within country variability by excluding multinational organizations, and sampling only leaders from the dominant subculture "in order to predict national level behaviors". The GLOBE studies were silent on demographics of race, ethnicity, age and educational levels of the leaders; racial/ethnic composition of the organizations that they lead; or demograph

Table 1.

Leadership style: cultural orientation value dimensions (COV).

\section{COV Dimension}

Group Collectivism (GC1): I encourage group pride, loyalty and group cohesiveness even if individual goals suffer.

GC2: I encourage individuals to take pride in their individual accomplishments even if this is contrary to the group's wishes.

Institutional Collectivism (IC1): I try to maximize individual interests and accomplishments over that of the group in my pay and reward systems.

IC2: I engage in practices which encourage and reward collective action and group members taking pride in the accomplishments of the group.

Future Orientation (FO1): I emphasize planning ahead and planning for the future.

FO2: I emphasize having immediate rewards, and getting employees to focus on getting things done and solving immediate problems.

Performance Orientation (PO1): I encourage employees to strive for continuously improving their performance at all costs.

PO2: I cultivate a sense of loyalty and belongingness to the organization and encourage employees to work together in harmony with one another.

Humane Orientation (HO1): I try to be benevolent and compassionate, and feel responsible for promoting the well-being of my employees.

HO2: Individual responsibility and accomplishments are what counts; I expect individuals to take care of themselves.

Uncertainty Avoidance (UA1): Orderliness and consistency are important as well as reliance on social norms and rules for an organization to run well.

UA2: It is important to experiment to be innovative and to be more informal rather relying on contracts and formal rules to dictate behavior.

Assertiveness (A1): It is important to be assertive, confrontational and direct to get things done and communicate what I mean.

A2: It is important to emphasize cooperation and social relationships; this may mean being indirect to communicate what I mean.

Power distance (PD1): I expect subordinates to obey orders without question and respect the lines of authority.

PD2: I believe all members can contribute equally to an organization, and that a person's influence should be based on what they contribute irrespective of their position.

Gender egalitarianism (GE1): Men and women should participate differently according to socially prescribed norms.

GE2: Women should be given opportunities to redress past discrimination. 
Table 2.

Cultural endorsed leadership dimensions.

\begin{tabular}{|c|c|c|}
\hline CLT Dimension & GLOBE Anglo Mean & Diverse Group Mean (SD) \\
\hline $\begin{array}{l}\text { Charismatic/Valued based } \\
\text { Inspiring, motivating, and expecting high performance from others based on your core values }\end{array}$ & 6.05 & $5.90(1.26)^{*}$ \\
\hline $\begin{array}{l}\text { Team oriented } \\
\text { Emphasizing team building and implementing a common purpose or goal among team members }\end{array}$ & 5.74 & $5.83(1.25)$ \\
\hline $\begin{array}{c}\text { Participative } \\
\text { Involving others in making and implementing decisions }\end{array}$ & 5.73 & $6.07(1.07)^{* *}$ \\
\hline $\begin{array}{c}\text { Autonomous } \\
\text { Being individualistic, independent, and unique in your leadership style }\end{array}$ & 3.82 & $3.95(1.67)$ \\
\hline $\begin{array}{l}\text { Self-protective } \\
\text { Ensuring the safety and security of yourself in your role as leader }\end{array}$ & 3.08 & $3.45(1.60)^{* *}$ \\
\hline $\begin{array}{l}\text { Humane Oriented } \\
\text { Being supportive and considerate of your employees including compassion and being generous }\end{array}$ & 5.08 & $6.13(1.03)^{* *}$ \\
\hline
\end{tabular}

Note: Higher score indicates greater agreement. using one-sample t-tests, ${ }^{*} p<.05 ;{ }^{* *} p<.001$.

ics of the researchers collecting the data. Survey items which showed semantic variation across countries were deleted.

\section{Research Question}

This exploratory study examines leadership style, social identities, and lived experiences of diverse leaders in the US. It draws on Implicit Leadership theory to identify how diverse leaders perceive and experience their leadership. Specific research questions include:

1) What leadership styles do diverse racial/ethnic leaders endorse?

2) How do diverse racial/ethnic leaders perceive their leader, racial/ethnic, and gender identities and their influence of social identities on their leadership?

3) Do lived experiences associated with race, ethnicity, gender, and dominant-minority status influence their leadership?

4) Does the leadership profile of this diverse group parallel GLOBE Anglo profile?

\section{Method}

The study uses grounded theory research as a phenomenological method to generate a theory of leadership that is inclusive of dimensions of diversity rather than testing any existing theory since we are uncertain of any that are or are not suited for the population under investigation (Corbin \& Strauss, 2007; Lester, 1999). In examining leader experiences and perceptions, common themes associating leadership with social identities and lived experiences will be identified from the leaders' perspectives and do not want to privilege certain types of scientific knowledge or marginalize other viewpoints. Hence, the lived experiences or social situations form our unit of analysis using grounded theory research as a method to emphasize diverse local worlds, multiple realities, and their complexities (Charmaz, 2006) to study diverse racial/ethnic minority leaders in the US rather than drawing on theories that favor white males who are both dominant in leadership position and reflected in existing leadership theories.

\section{Measure}

An 85 item questionnaire on Survey Monkey was used to collect the data. This included 19 demographic questions on: age, ethnicity, race, gender, sexual orientation, marital status, number of generations in the US, highest educational degree, job title, and leadership experience. Leader was operationally defined as having (or having had) a title or formal position of managerial responsibility within an organization.

Perception and experience of leadership were measured by: 1) 32 questions on how they perceived and endorsed GLOBE CLT and COV leadership dimensions, and different leadership styles; 2) 19 questions on their perception of leader, ethnic, and gender identities; and 3) 15 questions on lived experiences associated with ethnicity, gender, and leadership using a 7-point Likert scale. Leaders were asked to rate: 1) their endorsement of leadership dimensions and leadership styles (see Tables 1 and 2); 2) strength of their social identities and their influence on leadership; and 3) statements of lived experience about their motivation, aspirations, perceptions, and challenges to leadership, and if these experiences were related to their gender or racial/ethnic statuses.

\section{Procedures}

An invitation with a link to Survey Monkey was sent out by the principal investigator to listserves of ethnic minority associations, divisions of the American Psychological Association (membership of 160,000 , and a public Facebook page on Diversity and Leadership. The goal was to reach a diverse sample of racial/ethnic leaders. The invitation called for leaders to "participate in a Leadership Survey to identify self-perceptions of leadership style, leadership experience, and identity". Participants were informed that the purpose of the study was "to identify factors which influence the exercise of leadership, and to examine if there are differences in the exercise of leadership that vary by race/ethnicity and gender".

\section{Sample}

A total of 367 respondents completed the surveys out of the 535 who signed in to Survey Monkey. There were 124 (33.9\%) males, and $240(65.3 \%)$ females; $3(0.8 \%)$ did not identify their gender. Of the total sample, $84.3 \%$ identified as heterosexual, $7.8 \%$ as gay/lesbian, and $3.0 \%$ as bisexual.

Breakdown by the five racial/ethnic groups in the sample is shown on Table 3. Asian Americans were overrepresented compared to US census. This response rate may have been 
Table 3.

Demographic data of the sample.

\begin{tabular}{cccccc}
\hline Ethnic Group & Frequency & Percent & Mean Age (SD) & Leader Experience (Yrs) & Work Experience (Yrs) \\
\hline Black/African Americans & 40 & 10.8 & $50.23(11.43)$ & 12.5 & 19.8 \\
White/Euro Americans & 185 & 50.0 & $54.53(11.52)$ & 13.16 & $9.14^{*}$ \\
Asian Americans & 78 & 21.1 & $43.2(12.85)^{*}$ & 12.99 & $13.8^{* *}$ \\
Latino Americans & 37 & 10.0 & $51.66(10.82)$ & 16.7 & 19.5 \\
Native Americans & 18 & 4.9 & $55.94(7.59)$ & 12.5 & 15.5 \\
Total & 367 & 99.2 & $51.44(12.30)$ & 20.2 \\
\hline
\end{tabular}

Note: $\mathrm{F}(\mathrm{df}=5, \mathrm{MS}=1482)=11.18, \stackrel{*}{p}<.01 ;{ }^{* *} p<.001$.

skewed by the fact that the principal investigator is an Asian American psychologist known in the professional community. Age of leaders in the sample ranged from 20 years to 88 years with a mean age of 51.4 years. Asians were significantly younger than all other groups by eight years; and Native Americans were older by four and a half years.

On immigration status, $62.8 \%$ of the Asian sample and $44.4 \%$ of Latino sample were first generation immigrants. Asians made up $54.4 \%$ of those who were first generation immigrants while Whites made up $63.5 \%$ of those who have been in the US for more than two generations; $X^{2}(15, \mathrm{~N}=364)=$ $134.5, p<.001$.

Of the total sample, $65.7 \%$ was married; $18.5 \%$ was single with significant between group differences, $X^{2}(20, \mathrm{~N}=367)=$ 46.0, $p<.001$. More Asians (33.8\%) and Blacks (20.6\%) were single, and more Native Americans (10\%) were divorced. Age and marital status was significantly correlated $(p<.001)$;

\section{Leadership Experience}

Those filling out the questionnaire with no leadership experience were eliminated from the analyses. Most of the leaders $(80.3 \%)$ were currently in a position of leadership; the remaining $18.9 \%$ had all been in leadership positions. Mean number of years in a leadership position for the total sample was 12.5 years $(\mathrm{SD}=10.03)$. Asians had the fewest years of leadership experience, $(p<.01)$ and Native Americans had the most (see Table 3).

Mean numbers of years of work experience was 20.2 years $(\mathrm{SD}=12.2)$ with significant between group differences. Asians worked 10 years fewer than Whites who worked the most number of years (see Table 3); this is related to the age differences in the sample. One quarter $(26.5 \%)$ of the leaders also served in a volunteer service leadership position (e.g., professional or non-profit community board or association). Their service leadership roles included being president, board chair, division chair or executive committee member.

Leaders were primarily human services professionals from: education $(47.8 \%)$; health care practice $(14.1 \%)$; management $(11.9 \%)$; and social sciences $(11 \%)$. Their primary work settings included: higher education (53.9\%), psychology (34.1\%), government $(11.7 \%)$, non-profit community agencies $(12.0 \%)$, and corporate/business sector (13.5\%). More Native Americans $(25.8 \%)$ worked in government settings. More Asian Americans worked in non-profit (22.9\%) settings and fewer worked in higher education $(28.1 \%)$ compared to the other racial/ethnic groups.

The educational level of all leaders was at the MA level or higher; 76.8\% had completed a doctorate. Fewer Asians (53.8\%) and Latinos (67.6\%) had a doctoral degree compared with the other groups where more than $80 \%$ had doctoral degrees, $X^{2}$ (df $=5, \mathrm{~N}=367)=37.08, p<.000$.

\section{Results}

\section{Leadership Style: Culturally Endorsed Leadership Dimensions (CLT)}

Leaders from all five groups highly endorsed four of the six CLT leadership dimensions (Charismatic/value based, Team oriented, Participative, and Humane oriented) as reflective of how they lead ( $\mathrm{M}=5.83$ to 6.13 ), and eschewed two (Autonomous and Self-Protective), $\left(\mathrm{X}^{2}=376, \mathrm{df}=14, \mathrm{~N}=267, p\right.$ $<.001)$ as not consistent with good leadership with no significant between group differences. The total group CLT Leader Profile differed significantly from the GLOBE Anglo profile; total group means were higher on Humane Oriented, Self-Protective, and Participative CLT dimensions (t-test, $p<.001)$ and lower on Charismatic/Value based (t-test, $p<.05$ ) (see Table 2).

\section{Advocacy and Service Leadership}

Those leaders also serving on some volunteer leadership position were significantly lower on two of the CLT dimensions. They were less likely to endorse the Autonomous $(\mathrm{M}=3.53$, $\mathrm{SD}=1.55$ vs. $\mathrm{M}=4.10, \mathrm{SD}=1.68$, t-test, $p<.01$ ), and the Self-Protective dimensions $(\mathrm{M}=3.16, \mathrm{SD}=1.58$ vs. $\mathrm{M}=3.56$, $\mathrm{SD}=1.61$, t-test $p<.05)$.

\section{Aspirational Leadership Style}

$48.1 \%$ of all leaders aspired to be collaborative in their leadership style while $35.9 \%$ aspired to be transformational in their leadership style. Few chose charismatic or self-reflection leadership styles.

\section{Leadership Style: Cultural Orientation Value Dimensions (COV)}

Means and standard deviations for COV dimensions are shown on Table 4. As a group, leaders endorsed dimensions with ratings of 5 and above that were associated with encouraging group pride and collective action; getting things done and 
Table 4.

Cultural orientation value dimensions (COV).

\begin{tabular}{ccc}
\hline COV Dimension & $\begin{array}{c}\text { GLOBE US } \\
\text { Mean (SD) }\end{array}$ & $\begin{array}{c}\text { Total Group } \\
\text { Mean (SD) }\end{array}$ \\
\hline Group Collectivism $^{1}$ & $5.77^{* *}$ & $4.93(1.46)$ \\
Group Collectivism $^{2}$ & $5.77^{* *}$ & $3.84(1.58)$ \\
Institutional Collectivism $^{1}$ & $4.17^{* *}$ & $3.37(1.58)$ \\
Institutional Collectivism $^{2}$ & $4.17^{* *}$ & $5.41(1.29)$ \\
Future Orientation $^{1}$ & $5.31^{* *}$ & $4.41(1.36)$ \\
Future Orientation $^{2}$ & $5.31^{* *}$ & $5.84(1.10)$ \\
Performance Orientation $^{1}$ & 6.14 & $5.87(1.15)$ \\
Performance Orientation $^{2}$ & $6.14^{* *}$ & $4.12(1.53)$ \\
Humane Orientation $^{1}$ & $5.53^{* *}$ & $3.84(1.58)$ \\
Humane Orientation $^{2}$ & $5.53^{* *}$ & $6.03(1.13)$ \\
Uncertainty Avoidance $^{1}$ & $4.0^{* *}$ & $5.16(1.31)$ \\
Uncertainty Avoidance $^{2}$ & $4.0^{* *}$ & $4.82(1.25)$ \\
Assertiveness $^{1}$ & $4.32^{* *}$ & $4.72(1.53)$ \\
Assertiveness $^{2}$ & $4.32^{*}$ & $3.62(1.56)^{3}$ \\
Power Distance $^{1}$ & $2.85^{* *}$ & $5.27(1.41)$ \\
Power Distance $^{2}$ & $2.85^{*}$ & $2.55(1.49)^{1}$ \\
Gender Egalitarianism $^{1}$ & 5.06 & $4.90(1.85)^{2}$ \\
Gender Egalitarianism $^{2}$ & $5.06^{* * *}$ & $1.71(1.25)$ \\
\hline
\end{tabular}

Note: Globe vs. total group 1 -sample t-tests ${ }^{*} p<.05,{ }^{* *} p<.001$. ethnic group differences ANOVA ${ }^{1} p<.05,{ }^{2} p<.005,{ }^{3} p<.001$

solving immediate problems, encouraging employees to strive for continuous improvement, emphasizing individual and social responsibility, orderliness and reliance on social norms, and expecting subordinates to obey orders and respect authority.

Factor analysis of the COV dimensions yielded five factors; Factor 1 accounted for $23.9 \%$ and Factor 2 accounted for $13.5 \%$ of the variance. ANOVA tests showed no significant differences between groups on Factor 1 although White means $(\mathrm{M}=$ $-.128, \mathrm{SD}=.71)$ were negative compared to all other groups which were positive (ranging from .017 to .170). Factor 1 had high loadings on most COV dimensions, but was low for expecting women and men to follow socially prescribed roles or maximizing individual interests over that of the group. Factor 2 had high positive loadings on Humane Orientation of benevolence and compassion, maximizing individual accomplishments and pride, and believing all members can contribute equally to an organization, and high negative loadings Collectivism dimensions when they meant going against individual or group interests, and Performance Orientation: continuous improvement at all costs; ANOVA tests showed significant between group differences, $\mathrm{F}(\mathrm{df}=5, \mathrm{MS}=2.37)=2.43, p<.05$. Asians ranked highest $(\mathrm{M}=.36, \mathrm{SD}=1.05)$ while Latinos ranked lowest on this factor $(\mathrm{M}=-.47, \mathrm{SD}=.95)$.

Significant between group differences emerged on three of the Cultural Orientation Value dimensions: Assertiveness, em- phasizing cooperation and social relationships; Power Distance, all members can contribute equally; and Gender Egalitarianism, men and women should participate differently according to socially prescribed norms. Asians differed from other groups on all three dimensions $(p<.001)$ with an emphasis on egalitarianism, and endorsed benevolence, communication and being indirect, planning for the future, individual accomplishments, and loyalty to the group. Native Americans endorsed Collectivism and Humane orientations more highly than all other groups, expecting respect for authority, Assertiveness, being more direct and confrontational, while eschewing orderliness and not relying on social norms and rules for an organization to run well. Latinos endorsed Collectivism-emphasizing group pride and collective action over emphasizing individual interests although they emphasized individual responsibility; they also emphasized the present and getting things done. Blacks deemphasized reliance on rules and social norms and positions but endorsed being innovative and informal more highly than the other groups; they also emphasized cooperation and loyalty to the group. Blacks and Latinos were more likely to endorse the statement that men and women need to follow socially prescribed norms. Whites were low on Collectivism, put less emphasis on action and planning, and on respect for authority and social position. Comparison of differences between COV leadership profiles of the Total group with the GLOBE US profile using 1 -sample T-test were all significant $(p<.001)$ except for two dimensions (see Table 4).

\section{Social Identities: Intersectionality of Leader, Ethnic, and Gender Identity}

Most leaders strongly identified themselves as a leader $(\mathrm{M}=$ $5.35, \mathrm{SD}=1.36$ ) with no significant differences between groups. Diverse leaders of color, however, differed significantly from White leaders in how strongly they identified with their ethnic identity and whether they felt it influenced their exercise of leadership (t-test, $p<.001$ ). They were more likely to view their ethnicity as a strength, but not as a weakness. They were more like to feel their ethnicity posed significant barriers in accessing leadership roles. Asians were significantly more likely to experience their ethnicity as a weakness while Latinos were significantly more likely to feel ethnicity posed access barriers compared to other groups. White male leaders consistently rated all five questions related to ethnicity lower $(\mathrm{M}=$ 1.90 to 3.70) compared with diverse leaders of color $(\mathrm{M}=2.79$ to 6.07), see Table 5.

Women leaders identified more strongly with their gender than men (t-test, $p<.001)$. They were more likely to feel their gender influenced their exercise of leadership, and was a strength in their exercise of leadership. There were significant interaction effects between gender and ethnicity. White and Asian males felt gender did not influence their exercise leadership while Latino males did. White female leaders were less likely to feel that gender influenced their leadership while Black males were less likely to feel gender was a weakness compared with other groups (see Table 6).

\section{Lived Experiences: Perceptions and Expectations of Leadership}

Cultural and gender variation was evident in the lived experiences despite many group commonalities. Leaders chose 
Table 5.

Ethnic identity and leadership.

\begin{tabular}{|c|c|c|c|}
\hline Ethnic Identity & Mean (SD) White & Mean (SD) Diverse & Ethnic Group Means ${ }^{1}$ \\
\hline How strongly do you identify with your primary ethnicity? & $3.70(1.74)$ & $6.07(1.22)^{* * *}$ & $\begin{array}{c}\text { White (3.71) Asian (5.66) } \\
\text { Hispanic (6.25) Black (6.38) } \\
\text { Native (6.53) }\end{array}$ \\
\hline $\begin{array}{c}\text { Feel your ethnicity is a strength in your exercise of } \\
\text { leadership? }\end{array}$ & $3.03(1.82)$ & $5.35(1.75)^{* * *}$ & $\begin{array}{c}\text { White (3.03) Asian (4.84) } \\
\text { Hispanic (5.36) Black (5.45) } \\
\text { Native (6.67) }\end{array}$ \\
\hline $\begin{array}{c}\text { Feel your ethnicity is a weakness in your exercise of } \\
\text { leadership? }\end{array}$ & $1.98(1.27)$ & $2.79(1.78)$ & White (1.98) vs. Asian $(2.96)^{* *}$ \\
\hline $\begin{array}{l}\text { Feel your ethnicity posed barriers in your access to your } \\
\text { position(s) of leadership? }\end{array}$ & $1.90(1.35)$ & $4.16(2.03)^{* * *}$ & Asian (3.51) vs. Latino (5.11) \\
\hline Feel your ethnicity influences your exercise of leadership? & $3.03(1.77)$ & $5.14(1.64)^{* * *}$ & $\begin{array}{c}\text { White (3.02) Asian (4.55) } \\
\text { Black (5.24) Hispanic (5.62) } \\
\text { Native (6.00) }\end{array}$ \\
\hline
\end{tabular}

Note: Higher scores indicate greater agreement. ${ }^{1}$ ANOVA between group differences significant at $p<.001$ on all questions with whites differing from all groups of color. Other significant between group differences are noted.

Table 6.

Gender identity and leadership.

\begin{tabular}{|c|c|c|c|c|}
\hline Gender Identity & Mean (SD) Male & Mean (SD) Female & Mean (SD) Total & $F^{1}$ \\
\hline How strongly do you identify with your gender? & $5.10(1.61)$ & $5.76(1.43)$ & $5.54(1.52)^{* *}$ & 7.0 \\
\hline Felt gender influenced access to leadership & $3.99(1.88)$ & $3.94(2.06)$ & $3.96(1.99)$ & 0.3 \\
\hline Felt gender influenced exercise of leadership & $3.91(1.76)^{2}$ & $5.07(1.61)^{3}$ & $4.67(1.75)^{* * *}$ & 15.5 \\
\hline Feel gender is a strength & $3.83(1.73)$ & $4.86(1.72)$ & $4.51(1.79)^{* * *}$ & 11.5 \\
\hline Feel gender is a weakness & $2.55(1.38)$ & $3.09(1.71)^{4}$ & $2.90(1.62)^{*}$ & 3.6 \\
\hline
\end{tabular}

Note. Higher means indicate a greater level of agreement. 1 ANOVA $(2$, df within $),{ }^{*} p<.01 ;{ }^{* *} p<.001 ;{ }^{* * *} p<.000 .2$ white and asian males low vs. latino males high ${ }^{* * *} .3$ white females were low ${ }^{* * *} .4$ black males were low ${ }^{* *}$.

"the opportunity to make a difference" $(89.6 \%)$ as the most important reason for their motivation to be in a leadership role. "Competitive goals" (25.7\%) and "fell into the role" $(27.8 \%)$ were the next most important reasons. $37.5 \%$ of Native Americans and $48.8 \%$ of Asians chose "fell into the role" as reasons, higher than all other groups. While other reasons were chosen less than $16 \%$ of the time among all groups,

Blacks and Latinos chose "power", status", "monetary rewards", and "competitive" more often (20\% - 28\%); Native Americans were remarkably low copared to other groups (1\% $4 \%$ ), and high on choosing "opportunity to make a difference" and "fell into the role" $(38.5 \%)$ as their primary reasons.

Leaders rated a "personal trait (i.e., self-determination)" as the most influential factor in their access to or exercise of leadership $(\mathrm{M}=5.69, \mathrm{SD}=1.35)$, and "being mentored" as second most important ( $\mathrm{M}=4.70$, SD 2.09). Female leaders and leaders of color were significantly more likely to feel that having a role model of the same gender or ethnicity respectively was influential on their leadership (see Tables 7 and 8). This was most important to Black leaders and least important to White leaders, $\mathrm{F}=3.855(\mathrm{df}=5, \mathrm{MS}=18.06), p<.001$.

While all leaders felt they were effective as leaders $(\mathrm{M}=$ $5.48, \mathrm{SD}=.98)$, all group moderately worried about their leader behaviors $(M=4.33, S D=1.75)$. Although all ratings of perceptions and role expectations were less than 3, diverse leaders of color felt greater challenges to their leadership, negativity of these challenges, and expectations to behave according to socially prescribed perceptions of ethnicity compared to White leaders, $\mathrm{F}=18.37$, $(\mathrm{df}=5, \mathrm{MS}=59.78), p<.001$. Diverse leaders of color felt they had to prove themselves, and experienced greater discrepancies between self-appraisals and others' appraisals; these were all significant (see Table 7).

Asians felt "their ethnicity was a weakness" while all feeling less challenged compared to other leaders of color. Asians and Latinos were less likely to "feel they were effective as a leader" and felt a greater discrepancy compared to Blacks and Whites, $\mathrm{F}=2.8(\mathrm{df}=5, \mathrm{MS}=6.68), p<.01)$. Asians, Latinos, and Blacks "worried about their leader behaviors" more, and "felt they had to prove themselves as leaders" more compared with Whites and Native Americans.

While there were no between ethnic group differences on gender, women leaders were more likely to experience the influence of gender on their leadership experiences. They were more likely to feel challenged as to their effectiveness, more likely to feel they were expected to behave according gender roles, and to feel these expectations and challenges to their effectiveness as leaders were more negative (see Table 8).

\section{Discussion}

Using an Implicit Leadership framework, common themes emerged which support the importance of cultural values and 
Table 7.

Influence of ethnicity on leadership experiences.

\begin{tabular}{|c|c|c|c|}
\hline Lived Experiences & Mean (SD) White & Mean (SD) Diverse & $t(d f)$ \\
\hline Worry about leader behaviors? & $4.03(1.79)$ & $4.33(1.75)$ & $.44(281)$ \\
\hline Feel you have to prove yourself? & $3.05(1.67)$ & $3.47(1.82)^{*}$ & $-2.13(280)$ \\
\hline Feel you are effective as a leader? & $5.48(.98)$ & $5.36(1.07)$ & $-.81(280)$ \\
\hline Discrepancy between how others rate you and yourself? & $2.98(1.48)$ & $3.66(1.52)^{* * *}$ & $5.98(280)$ \\
\hline $\begin{array}{c}\text { Felt ethnicity contributed to performance appraisals of your } \\
\text { effectiveness? }\end{array}$ & $2.16(1.39)$ & $4.42(2.01)^{* * *}$ & $6.16(280)$ \\
\hline Felt challenged on effectiveness because of ethnicity? & $1.71(1.37)$ & $3.86(2.07)^{* * *}$ & $5.83(271)$ \\
\hline $\begin{array}{c}\text { Felt challenged on leadership style because of gender or } \\
\text { ethnicity? }\end{array}$ & $2.90(2.00)$ & $3.76(2.00)^{*}$ & $2.16(269)$ \\
\hline $\begin{array}{c}\text { How negative were these challenges on leadership style because } \\
\text { of your ethnicity? }\end{array}$ & $1.62(1.15)$ & $3.98(2.04)^{* * *}$ & $6.27(270)$ \\
\hline Expected to behave in way related to perception of ethnicity? & $1.89(1.54)$ & $3.93(2.07)^{* *}$ & $5.47(269)$ \\
\hline $\begin{array}{l}\text { How negative were these expectations according to the } \\
\text { perception of your ethnicity? }\end{array}$ & $1.78(1.37)$ & $3.87(2.02)^{* * *}$ & $5.58(268)$ \\
\hline $\begin{array}{l}\text { How influential or beneficial was having a role model of your } \\
\text { own ethnicity? }\end{array}$ & $3.24(2.16)$ & $3.69(2.21)^{*}$ & $2.17(267)$ \\
\hline
\end{tabular}

Note: Higher scores indicate greater level of agreement. white vs. diverse ${ }^{*} p<.05 ;{ }^{* *} p<.01 ;{ }^{* * *} p<.001$.

Table 8.

Influence of gender on leadership experiences.

\begin{tabular}{|c|c|c|c|c|}
\hline Lived Experience & Mean (SD) Male & Mean (SD) Female & Mean (SD) Total Group & $t$ (df) \\
\hline $\begin{array}{l}\text { Felt gender contributed to performance } \\
\text { appraisal? }\end{array}$ & $3.52(1.84)$ & $4.31(1.92)$ & $4.05(1.93)^{* *}$ & $-3.32(276)$ \\
\hline $\begin{array}{l}\text { Felt challenged on effectiveness because of } \\
\text { gender? }\end{array}$ & $1.94(1.37)$ & $3.61(2.03)$ & $3.06(2.02)$ & $-7.10(268)$ \\
\hline $\begin{array}{l}\text { How negative were these challenges } \\
\text { because of your gender? }\end{array}$ & $2.09(1.52)$ & $3.72(2.04)$ & $3.17(2.03)^{* *}$ & $-6.73(267)$ \\
\hline $\begin{array}{l}\text { Expected to behave in way related to } \\
\text { perceptions of gender roles? }\end{array}$ & $2.62(1.85)$ & $3.84(2.18)$ & $3.44(2.16)^{* *}$ & $-4.56(267)$ \\
\hline $\begin{array}{l}\text { How negative were these expectations to } \\
\text { behave? }\end{array}$ & $2.40(1.62)$ & $3.88(2.08)$ & $3.40(2.07)^{* *}$ & $-5.91(266)$ \\
\hline $\begin{array}{l}\text { How influential or beneficial was having a } \\
\text { role model of your own gender? }\end{array}$ & $4.02(1.95)$ & $4.85(2.05)$ & $4.54(2.06)^{* *}$ & $-3.15(260)$ \\
\hline
\end{tabular}

Note: Higher scores indicate greater level of agreement. ${ }^{* *} p<.001$.

beliefs, social contexts as well as minority status in shaping the leadership experiences of leaders in this study. Leaders in this study differed from leaders in the GLOBE studies in several significant ways. GLOBE leaders were drawn to be homogenous within their countries, and from food processing, finance, and telecommunications industries. This study was intentionally heterogeneous in recruiting diverse racial/ethnic leaders. It yielded a sample of $50 \%$ racial/ethnic minority leaders and $65 \%$ female leaders drawn from human service industries within the US. While the five groups differed in terms of race and ethnicity, four of the groups shared experiences of minority status within the US.

\section{Endorsement of Leadership Styles}

Leaders across all five racial/ethnic groups endorsed and eschewed leadership dimensions consistent with the "universal" dimensions found in the GLOBE studies as contributing to or impeding outstanding leadership. Their CLT leadership profile differed significantly from the GLOBE Anglo profile suggest that differing social contexts, lived experiences, and cultural subgroup differences help to shape leadership style. Leaders in this study were higher on Humane, Self-Protective and Participative CLT leadership dimensions and lower on Charismatic dimension compared to the GLOBE Anglo profile. A more humane orientation can partially attributable to minority status in which experiences of being marginalized and conferred outsider status enable leaders to be more empathic with their subordinates. At the same time, racial/ethnic minority leaders are more likely to experience negative challenges to their leadership style and effectiveness as we find in the section on lived experiences which would render them to be more self-protective. Participative leadership is consistent with female gender roles and racial/ethnic cultural roles which value 
collaboration and collective action. A humane orientation is also consistent with service and helping aspects of human service professions; leaders in this study who were active in advocacy and service leadership activities were found to be less autonomous and self-protective, presumably being unified in collective activity. The endorsement of a collaborative style in the aspirational ratings together with a low endorsement of a Charismatic orientation among these leaders may reflect the growing importance of cultural values associated with collaboration endorsed by racial/ethnic minorities and women in the US as well as growth in their numbers within ranks of leadership in contemporary society where charismatic leadership is viewed as characteristic of white privilege and male dominance. These findings argue for a more complex understanding of national profiles to define leadership styles to be inclusive of diversity and subgroup differences.

\section{Leadership Style: Cultural Variation on Collectivism and Humane Orientations}

Cultural Orientation Value dimensions highlight both a universal set of dimensions consistent with good leadership as well as important differences across racial/ethnic groups. Factor 1 of the COV dimensions reflects this complexity of group pride and collective action, a reliance on social norms and respect for authority, an emphasis on future and performance orientation consistent with the motivation to lead, and task orientation skills useful to the exercise of leadership. It also includes an emphasis on individual and social responsibility, performance orientation and accomplishment consistent with core values of those with higher educational levels.

Variation between the diverse racial/ethnic groups emerged on COV factor 2 which includes benevolence and compassion consistent with a humane orientation, and an emphasis on caring for individual needs. Diverse leaders of color endorsed collective dimensions more strongly than White leaders. However, the negative loadings on two dimensions of collectivism suggest that collectivism was not endorsed when it meant going against individual or group interests for the sake of the other. It is also likely that when these rewards result in exclusion, reinforcing the status quo of institutions that have been prejudicial against minorities, it is inconsistent with a social justice orientation that emphasizes fairness. For racial/ethnic minorities, institutional collectivism as framed by the questions may have been viewed with skepticism as referencing mainstream institutions which have not cared for or dealt fairly with its members, and their historical experience as an out group.

Asians differed significantly from other groups with their emphasis on egalitarianism, individualism and collectivism. They endorsed an emphasis on social order, benevolence, loyalty to the group, and social and interpersonal communication using indirect means - all consistent with Confucian Asian values. At the same time, they endorsed planning, individual accomplishment, and rewarding individual effort and eschewed emphasis on some collectivist dimensions. Their endorsement of Assertiveness defined as emphasizing cooperation and social relationships using indirect means of communication suggests that these dimensions may carry different semantic meanings. Asians in this group may be experiencing greater transition in their sociocultural roles, both as younger, less experienced leaders and as first generation immigrants. Their profile may reflect an emphasis on merit as a cultural value over an empha- sis on hierarchy as they grapple with acculturation and achievement compared with other groups in the study. Fung, Ho, Tam, Tsai, \& Zhang (2011) found age related changes in endorsing cultural orientations which interacted with ethnicity. Older Chinese Americans endorsed a relationship orientation (i.e., refraining from offending others even at the expense of personal pleasure) more than younger Chinese Americans; but this trend was not found among European Americans, or was weaker among Chinese Americans who valued Hedonism (seeking individual pleasure).

Native Americans distinguished themselves on the COV dimensions with a more collectivistic and humane orientation, emphasizing group pride and accomplishments as well as benevolence and compassion. They were more likely to endorse "being confrontational and direct in getting things done" while minimizing being indirect in their social relationships, or "expecting subordinates to obey orders and respect lines of authority and respecting hierarchy". This may reflect their adapting to mainstream leadership contexts by both conforming to the "rules of the game" while also maintaining their group pride and cultural values. Given their cultural history in the US and their greater experience as leaders, their lesser concern with rules and order or competition may reflect their "refusal to buy into mainstream US" rules and culture

These leadership profiles are all relative although they do reflect cultural values, lived experiences as well as the particular contexts in which they are situated. Latinos emphasized Collectivism even over individual interests although they also emphasized individual responsibility and conforming to socially prescribed gender roles; this seems consistent with the importance of familismo as a cultural value. Blacks emphasized innovation and informality, group loyalty, and took a middle of the role position on most of the dimensions.

\section{Social Identities: Intersection of Ethnicity, Gender with Leader Identity}

Social identities associated with gender and ethnicity and their intersection clearly distinguished diverse leaders of color from white leaders. While racial/ethnic and gender identities could be used as a resource which leaders bring, they also present challenges to authenticity. Can one be authentic and true to oneself as urged by contemporary leadership theorists (Avolio, Gardner, Walumbwa, Luthans, \& May, 2004), or do diverse leaders of color lose themselves as they negotiate across social contexts because of different cultural orientation values, group affiliation status, and dominant-minority status. While the ability to code switch or present "different selves" can be viewed as adaptive, as fitting in, and may be advantageous in enabling leaders to be more flexible or bring new perspectives, this behavior can also be viewed with mistrust as being inauthentic.

Diverse leaders of color felt their social identities influenced their leadership behaviors. With Asian and Native American leaders more likely to "fall into the role" consistent with cultural values which emphasize modesty, cooperation and harmony with the environment, they often need to be pushed into leadership positions, and may be perceived as less aggressive in their leadership behaviors.

The importance of social identities among diverse leaders of color makes for a different leadership experience. Their contribution to intergroup leader-member dynamics will need further investigation. What happens when we bring together leaders and members with different social identities? How does the 
intersection of social identities between leaders and members influence levels of trust, communication, teamwork, and problem solving? How do we build strategies for affirming these identities so as to promote rather than impede effective leadership?

\section{Lived Experiences Interact with Perceptions and Role Expectations}

While all groups share commonalities of perceiving themselves as effective leaders, racial/ethnic leaders and women leaders share a common experience of minority status. These lived experiences associated with minority status, gender and ethnic roles do influence leader behaviors, perceptions, and role expectations. Diverse leaders of color and women leaders were more likely to feel challenges to their leadership, and to feel expectations that they conform to stereotypic racial/ethnic or gender roles, creating a different context for their leadership. More energy is spent having to prove themselves, and negotiating the negative impact on performance appraisals. Striking throughout the responses was how leaders' perceptions and experiences reflected a tendency to use their experiences of marginalization and minority status as a resource and strength rather than as a weakness. Further research could identify factors contributing to resiliency to face these negative challenges, identifying strategies for diverse leaders to adapt to leadership contexts which demand different skills than those prescribed by their own cultural orientation values. Some of the differences between diverse leaders of color and White leaders in this study may reflect coping mechanisms associated with minority status which these leaders bring and use as personal resources for their leadership, e.g., self-determination, high Performance Orientation. COVs such as the Humane Orientation found in this group may reflect the social justice orientation they bring to their leadership. Does minority status confer outsider status that cannot be bridged? Are diverse leaders of color bound by negative consequences of stereotypic role expectations? These are questions for further research as well as the need to affirm social identities as important to the exercise of leadership.

We need to examine incongruities between socially prescribed ethnic and gender roles and leadership roles. In the case of women leaders, this incongruity has had both disadvantages and advantages; women leaders are often praised for having excellent skills for leadership because of their interpersonal and communication styles while viewed as weak or indecisive when they attempt to be collaborative (Eagly, 2007). While not yet confirmed in leadership studies, Blacks often are viewed as being angry when being assertive; Asians often are viewed as passive when being modest or using indirect means of communication; Latinos often are viewed as overly emotional when expressing enthusiasm. How do we help leaders to use these incongruities as personal resources in their leadership? The emphasis on collaborative leadership over charismatic and transformational leadership in this study is illuminating. While definitions may vary, does it reflect the different perspective brought by diverse leaders of color who may view a charismatic leader as boastful and shallow over that of a humane leader who is viewed as self-sacrificing and benevolent?

\section{Implications}

This exploratory study identified cultural variation in leadership styles, social identities and lived experiences among lead- ers from five diverse racial/ethnic groups within the US. In examining the experiences and perceptions of leaders from their own perspectives, this study was intended to challenge normative assumptions and conventional wisdom that we take for granted associated with traditional leadership paradigms. Using Implicit Leadership theory as a framework to examine their leadership experiences and perceptions, their social realities was a start toward incorporating diversity into our understanding of leadership. Differences between diverse leaders of color and women leaders make for a different leadership experience which warrants further investigation. This might include the sharing and distribution of power when leaders hold minority status of different cultural orientation values amidst different member compositions and organizational contexts. Cultural variation in semantic meaning in these "universal dimensions" would be another fruitful direction. Is transformational leadership uniformly defined and valued across cultural groups? How is assertiveness viewed across cultural groups, as confrontational and direct or as social and interpersonal engagement to get one's point across? How might the racial/ethnic and gender composition of leaders and members influence the use competition or cooperation to achieve organizational outcomes?

Diversity leadership is an attention to the social identities and larger sociocultural context of which leaders are a part as well as the leader-member composition within different organizational contexts. Recognizing the intersectionality of gender and ethnic identities with leader identity, and the significance of lived experiences associated with minority status enables us to ask questions about how social justice, humane, and collectivist orientations informs the exercise of leadership, decision making and managing of workgroup teams within an organization. This use of an affirmative paradigm to reframe the leadership context can be used to promote flexibility and innovation in leadership behaviors and enable diverse leaders to draw on their experiences of living in bicultural environments, needing to code switch, and having to grapple with multiple social identities. Diversity leadership is to be inclusive of all groups and all perspectives.

\section{Acknowledgements}

The author thanks Hui Mei Nan for her diligent coding and analysis of the data.

\section{REFERENCES}

Avolio, B. J., Gardner, W. L., Walumbwa, F. O., Luthans, F., \& May, D. R. (2004). Unlocking the mask: A look at the process by which authentic leaders impact follower attitudes and behavior. The Leadership Quarterly, 15, 801-823. doi:10.1016/j.leaqua.2004.09.003

Ayman, R., \& Korabik, K. (2010). Leadership: Why gender and culture matter. American Psychologist, 65, 157-170. doi: $10.1037 / \mathrm{a} 0018806$

Charmaz, K. (2006). Constructing grounded theory. London: Sage.

Chin, J. L. (2010). Introduction to the special issue on diversity and leadership. American Psychologist, 65, 150-156. doi: $10.1037 / \mathrm{a} 0018716$

Chin, J. L., \& Sanchez-Hucles, J. (2007). Diversity and leadership. American Psychologist, 62, 608-609. doi:10.1037/0003-066X62.6.608

Corbin, J., \& Strauss, A. (2007). Basics of qualitative research: Techniques and procedures for developing grounded theory (3rd ed.). Thousand Oaks, CA: Sage.

Den Hartog, D. N., \& Dickson, W. (2004). Leadership and culture. In A. 
T. J. Antonakis (Ed.), The nature of leadership (pp. 249-278). Thousand Oaks, CA: Sage.

Eagly, A. E. (2007). Female leadership advantage and disadvantage: Resolving the contradiction. Psychology of Women Quarterly, 31, 112. doi:10.1111/j.1471-6402.2007.00326.x

Eagly, A. H., \& Carli, L. I. (2007). Throught the labyrinth: The truth about how women become leaders. Boston, MA: Harvard Business School Press.

Eagly, A. H., \& Chin, J. L. (2010). Diversity and leadership in a changing world. American Psychologist, 65, 216-224.

doi: $10.1037 / \mathrm{a} 0018957$

Eagly, A. H., \& Karau, S. J. (2002). Role congruity theory of prejudice toward female leaders. Psychological Review, 109, 573-598. doi:10.1037/0033-295X.109.3.573

Eagly, A., Mahijani, M., \& Konsky, B. (1992). Gender and the evaluation of leaders: A meta-analysis. Psychological Bulletin, 117, 125145. doi:10.1037/0033-2909.117.1.125

Fassinger, R. E., Shullman, S. L., \& Stevenson, M. R. (2010). Toward an affirmative lesbian, gay, bisexual, and transgender leadership paradigm. American Psychologist, 65, 201-215. doi:10.1037/a0018597

Fung, H. H., Ho, Y. W., Tam, K.-P., Tsai, J., \& Zhang, X. (2011). Value moderate age differences in relationship orientation. Personality and Individual Differences, 50, 994-999. doi:10.1016/j.paid.2011.01.009

Gerstner, C. R., \& Day, D. V. (1994). Cross-cultural comparison of leadership prototypes. Leadership Quarterly, 5, 121-134. doi:10.1016/1048-9843(94)90024-8

Hackman, J. R., \& Wageman, R. (2007). Asking the right questions about leadership: Discussion and conclusions. American Psycholo- gist, 62, 43-48. doi:10.1037/0003-066X.62.1.43

Hofstede, G. (2001). Culture's consequences: International differences in work-related values (2nd ed.). Thousand Oaks, CA: Sage.

House, R. J., Hanges, P. J., Javidan, M., Dorfman, P. W., \& Gupta, V. (2004). Culture, leadership, and organizations: The GLOBE study of 62 societies. Thousand Oaks, CA: Sage.

Kao, H. S., Sinha, D., \& Wilpert, B. (1999). Management and cultural values: The indigenization of organizations in Asia. Thousand Oaks, CA: Sage Publications.

Lester, S. (1999). An introduction to phenomenological research. Stan Lester Developments, Taunton. http://www.sld.demon.co.uk/resmethy.pdf

Lord, R. G., \& Maher, K. J. (1991). Leadership and information processing. London: Routledge.

Ospina, S., \& Foldy, E. (2009). A critical review of race and ethnicity in the leadership literature: Surfacing context, power and the collective dimensions of leadership. The Leadership Quarterly, 20, 876896. doi:10.1016/j.leaqua.2009.09.005

Pittinsky, T. L. (2010). A two-dimensional model of intergroup leadership: The case of national diversity. American Psychologist, 65, 194200. doi:10.1037/a0017329

Ragins, B., Townsend, B., \& Mattis, M. (1998) Gender gap in the executive suite: CEOs and female executives report on breaking the glass ceiling. Academy of Management Executive, 12, 28-42.

Triandis, H. C. (1995). Individualism and collectivism. Boulder, CO: Westview Press.

Yukl, G. (1989). Managerial leadership: A review of theory and research. Journal of Management, 15, 251-289. doi: $10.1177 / 014920638901500207$ 